\title{
BMJ
}

\section{Acceptability and accuracy of a non-endoscopic screening test for Barrett's oesophagus in primary care: cohort study}

\author{
Sudarshan R Kadri, clinical research fellow in gastroenterology, ${ }^{1}$ Pierre Lao-Sirieix, group research manager, \\ Maria O'Donovan, consultant gastrointestinal pathologist, ${ }^{1,2}$ Irene Debiram, research nurse, ${ }^{1}$ Madhumita Das, \\ laboratory assistant, ${ }^{1}$ Jane M Blazeby, professor of surgery and honorary consultant oesophago-gastric \\ surgeon, ${ }^{3}$ Jon Emery, professor of general practice, ${ }^{4,5}$ Alex Boussioutas, senior lecturer and consultant \\ gastroenterologist, ${ }^{6}$ Helen Morris, senior research associate in public health and primary care, ${ }^{5}$ Fiona $\mathrm{M}$ \\ Walter, NIHR clinical lecturer in general practice, ${ }^{4,5}$ Paul Pharoah, reader in cancer epidemiology, ${ }^{7}$ Richard $\mathrm{H}$ \\ Hardwick, consultant oesophago-gastric surgeon, ${ }^{8}$ Rebecca C Fitzgerald, MRC programme leader and \\ honorary consultant gastroenterologist ${ }^{1}$
}

${ }^{1}$ MRC Cancer Cell Unit, HutchisonMRC Research Centre, Cambridge CB2 2XZ

${ }^{2}$ Department Histopathology, Addenbrooke's Hospital,

Cambridge

${ }^{3}$ Department of Social Medicine, University of Bristol

${ }^{4}$ School of Primary, Aboriginal and Rural Health Care, University of Western Australia, Australia

${ }^{5}$ General Practice and Primary Care Research Unit, University of Cambridge

${ }^{6}$ Department of Medicine, University of Melbourne, Western Hospital, Melbourne, Australia,

and Cancer Genomics and

Predictive Medicine, Peter

MacCallum Cancer Centre, East

Melbourne, Australia

${ }^{7}$ Strangeways Laboratory,

Department of Oncology, University of Cambridge

${ }^{8}$ Cambridge Oesophago-Gastric Centre, Addenbrooke's Hospital

Correspondence to: R C Fitzgerald rcf@hutchison-mrc.cam.ac.uk

Cite this as: $B M J$ 2010;341:C4372 doi:10.1136/bmi.c4372

\section{ABSTRACT}

Objectives To determine the accuracy and acceptability to patients of non-endoscopic screening for Barrett's oesophagus, using an ingestible oesophageal sampling device (Cytosponge) coupled with immunocytochemisty for trefoil factor 3.

Design Prospective cohort study.

Setting 12 UK general practices, with gastroscopies carried out in one hospital endoscopy unit.

Participants 504 of 2696 eligible patients (18.7\%) aged 50 to 70 years with a previous prescription for an acid suppressant $\left(\mathrm{H}_{2}\right.$ receptor antagonist or proton pump inhibitor) for more than three months in the past five years.

Main outcome measures Sensitivity and specificity estimates for detecting Barrett's oesophagus compared with gastroscopy as the ideal method, and patient anxiety (short form Spielberger state trait anxiety inventory, impact of events scale) and acceptability (visual analogue scale) of the test.

Results 501 of 504 (99\%) participants (median age 62, male to female ratio $1: 1.2)$ successfully swallowed the Cytosponge. No serious adverse events occurred. In total, $3.0 \%$ (15/501) had an endoscopic diagnosis of Barrett's oesophagus ( $\geq 1 \mathrm{~cm}$ circumferential length, median circumferential and maximal length of $2 \mathrm{~cm}$ and $5 \mathrm{~cm}$, respectively) with intestinal metaplasia. Compared with gastroscopy the sensitivity and specificity of the test was $73.3 \%$ (95\% confidence interval $44.9 \%$ to $92.2 \%$ ) and $93.8 \%$ (91.3\% to $95.8 \%$ ) for $1 \mathrm{~cm}$ or more circumferential length and $90.0 \%$ (55.5\% to $99.7 \%$ ) and $93.5 \%$ (90.9\% to $95.5 \%)$ for clinically relevant segments of $2 \mathrm{~cm}$ or more. Most participants (355/496, 82\%, 95\% confidence interval $78.9 \%$ to $85.1 \%$ ) reported low levels of anxiety before the test, and scores remained within normal limits at follow-up. Less than $4.5 \%$ (2.8\% to $6.1 \%)$ of participants reported psychological distress a week after the procedure.
Conclusions The performance of the Cytosponge test was promising and the procedure was well tolerated. These data bring screening for Barrett's oesophagus into the realm of possibility. Further evaluation is recommended.

\section{INTRODUCTION}

The incidence of oesophageal adenocarcinoma, for which Barrett's oesophagus is the main risk factor, has increased sixfold in the Western world since the 1990s. ${ }^{1}$ Meta-analyses suggest that the risk for conversion from Barrett's oesophagus to adenocarcinoma is $0.5 \%$ per year and this conversion is thought to occur up to 15 years after diagnosis. ${ }^{2}$ This cancer has in excess of $80 \%$ mortality at five years unless detected early (also called intraepithelial neoplasia). ${ }^{3}$ Oesophagectomy has formed the basis for curative treatment even in patients with surveillance detected asymptomatic disease. However, because of the $5 \%$ mortality and significant morbidity associated with this highly invasive surgery, little enthusiasm has been shown for diagnosing Barrett's oesophagus at a population level. The treatments for intraepithelial neoplasia in Barrett's oesophagus have recently undergone a paradigm shift with the rapid development of outpatient endoscopic technologies, such as mucosal resection and radiofrequency ablation. ${ }^{4-6}$ The feasibility for endoscopic treatment now means that more systematic screening for Barrett's oesophagus merits further consideration. ${ }^{7}$

The ideal method for diagnosing Barrett's oesophagus is white light gastroscopy and biopsy, despite limitations such as the invasiveness of the procedure, the need for great expertise, the high cost, and the subjective nature of the diagnosis. However, limited endoscopy and fiscal resources may restrict the use of this procedure in large, population based screening programmes, and many people may be reluctant to undergo hospital based gastroscopy because of its inconvenience and discomfort. ${ }^{89}$ 
As highlighted by the chief medical officer, Sir Liam Donaldson, in his 2008 report, a need exists for a safe, minimally invasive, cheap, and easily administered method aimed at the primary care setting to diagnose Barrett's oesophagus. ${ }^{710}$ We have shown that nonendoscopic screening is feasible and safe using a new device called the capsule sponge, or Cytosponge. ${ }^{11}$ To distinguish Barrett's cells from a mixed cell population, including gastric cardia and squamous epithelium, we have coupled the device with an immunohistochemical biomarker, trefoil factor $3 .^{11}$ We determined the accuracy and acceptability of using the Cytosponge combined with trefoil factor 3 as a non-endoscopic procedure for the detection of Barrett's oesophagus in primary care.

\section{METHODS}

This prospective cohort study was undertaken in 12 general practices in the United Kingdom. The outcome measures were sensitivity and specificity estimates for detecting Barrett's oesophagus compared with gastroscopy as the ideal method to inform a future study, and patient anxiety and acceptability of undergoing the test.

\section{Setting and recruitment}

We identified eligible patients by searching the prescribing database of the 12 primary care practices for adults aged 50 to 70 with a previous prescription for an acid suppressant $\left(\mathrm{H}_{2}\right.$ receptor antagonist or proton pump inhibitor) for more than three months in the past five years. Exclusion criteria were a previous diagnosis of Barrett's oesophagus, gastroscopy within the past year, dysphagia, known portal hypertension, drug or pathophysiological abnormality of coagulation, important physical or psychological comorbidity precluding gastroscopy, or the inability to provide informed consent. The number of general practices was based on previous studies based in primary care reporting that $16.3 \%$ of patients with reflux symptoms agreed to endoscopy. ${ }^{12}$ The general practices sent eligible participants an invitation letter. Responders who agreed to take part were sent an appointment for the Cytosponge test at the general practice. Recruitment continued until more than 500 people had participated.

\section{Study procedures}

Appointment in general practice and questionnaire follow-up After written informed consent had been obtained the participants completed a sociodemographic and clinical questionnaire and an assessment of symptoms (gastro-oesophageal reflux disease impact score ${ }^{13}$ ).

The research nurse or research fellow (gastroenterologist in specialist training) administered the Cytosponge, an ingestible gelatine capsule containing a compressed mesh attached to a string. The Cytosponge was approved by the UK Medical Health Regulatory Agency in 2008 (fig 1). Briefly, the capsule and bunched up string are swallowed with water. The string is held without any tension to allow the capsule to move into the stomach. The patient holds onto the string for five minutes after ingestion to allow the capsule to dissolve in the proximal stomach, where a spherical mesh of $3 \mathrm{~cm}$ diameter is released. The back of the throat is then sprayed with $1 \%$ lidocaine (lignocaine) and the expanded mesh withdrawn by pulling on the string with the patient's head in an extended position. After retrieval the string is cut and the Cytosponge containing the cytological specimen placed in preservative fluid (gift from Surepath; BD Diagnostics, Durham, NC, USA) and kept at room temperature until transportation to the laboratory. The whole process of administering the Cytosponge, including instructing the patient, takes less than 10 minutes.

Within 30 minutes of the procedure the participants completed a questionnaire including the short form Spielberger state trait anxiety inventory, ${ }^{14}$ the impact of events scale, ${ }^{15}$ and a visual analogue scale to measure acceptability. ${ }^{16}$ The short form Spielberger state trait anxiety inventory has been extensively used in studies of disease screening. We prorated the scores as per developers' guidelines, with a score of 40 or more considered to represent clinically significant anxiety. ${ }^{17} \mathrm{To}$ measure the effect of the Cytosponge on anxiety and distress we used the impact of events scale. The scale yields two scores assessing intrusive and avoidance thoughts. Final scores range between 0 and 35 for intrusion and 0 and 40 for avoidance (total score between 0 and 75), with values of more than 19 for each subscore (38 for total score) representing high test induced distress and values below 8.5 for each subscore (17 for total score) representing low distress. ${ }^{15} \mathrm{We}$ calculated scores for participants who completed a minimum of $75 \%$ of questions on each subscore. The visual analogue scale assessed acceptability of the procedure, where 0 represented the "worst experience" and 10 the "best experience." Similar questionnaires were posted to all participants seven and 90 days later. Non-responders were sent one postal reminder and if that failed one telephone reminder.

\section{Laboratory processing of samples}

To provide the patient with a prompt result we stored the Cytosponge samples at room temperature and

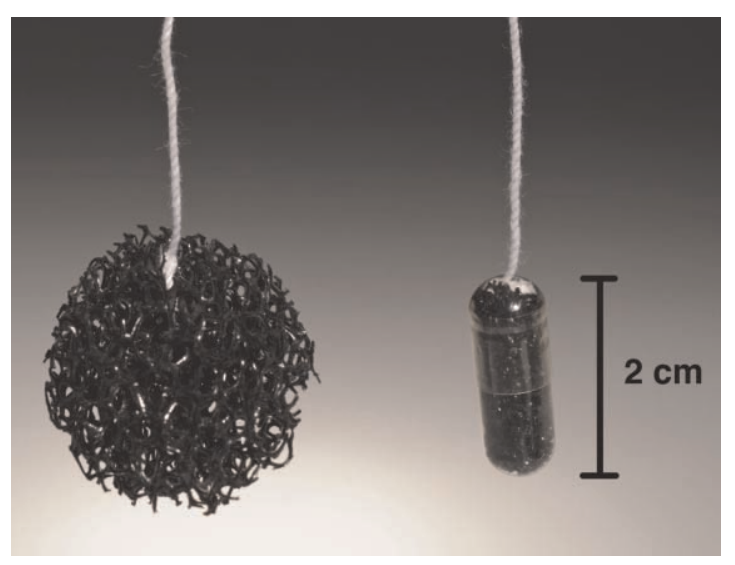

Fig 1 Cytosponge in gelatine capsule (right) and expanded (left) 


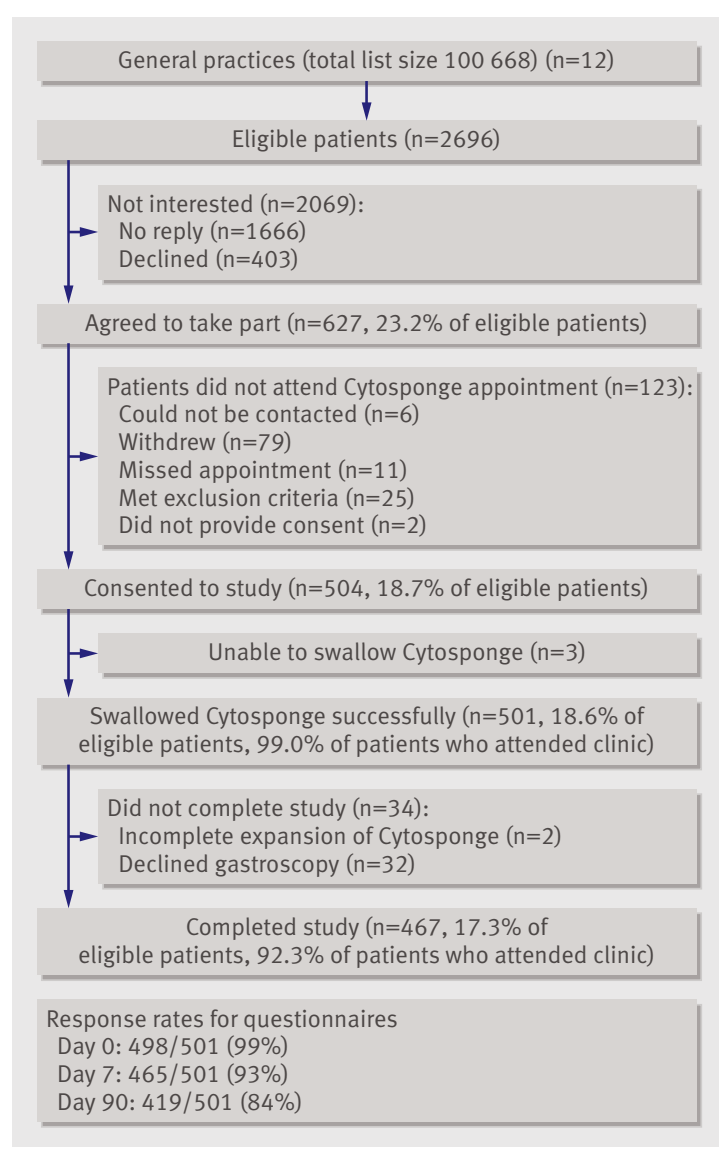

Fig 2 Flow of patients through trial

processed them within 48 hours; the samples can be stored in the refrigerator at $4^{\circ} \mathrm{C}$ before processing without affecting the assay result. Samples were processed to paraffin blocks. Immunostaining was carried out for trefoil factor 3, which we identified to be a diagnostic marker of Barrett's oesophagus from a systematic gene expression profiling experiment. ${ }^{11}$ Two independent researchers, one with expertise in pathology (SK) and a gastrointestinal cytopathologist (MO'D), reported the findings. Sections stained for trefoil factor 3 were scored in a binary fashion as either positive or negative. Any glandular cells with trefoil factor 3 staining were considered as positive and to make the result as robust and objective as possible we used no intensity cut offs. The $\kappa$ statistic between the two scorers was 0.74 , indicating substantial agreement.

\section{Gastroscopy: the ideal method}

We invited those participants who had swallowed the Cytosponge to attend for a gastroscopy within three weeks of the screening test. The gastroscopies were carried out at a single specialist unit by one of three endoscopists, who adhered to a strict diagnostic protocol. In view of the lack of a universally accepted definition for Barrett's oesophagus, ${ }^{1}$ we opted for criteria that would avoid mistaken identification of a hiatus hernia and that were in line with the Prague classification guidelines. These guidelines recommend the use of the length of Barrett's oesophagus from the gastro- oesophageal junction covering the circumference of the oesophagus (circumferential length or $\mathrm{C}$ ) and the maximal length of Barrett's oesophagus from the gastro-oesophageal junction (maximal length or $\mathrm{M}$ ) for a robust diagnosis. ${ }^{18}$ Hence a patient with $1 \mathrm{~cm}$ of circumferential Barrett's oesophagus with $2 \mathrm{~cm}$ of Barrett's tissue extending above the circumferential segment above with a total length of $3 \mathrm{~cm}$ is described as having Barrett's oesophagus C1M3. Barrett's oesophagus was defined as endoscopically visible columnar lined epithelium arising at least $1 \mathrm{~cm}$ circumferentially (C1) above the gastro-oesophageal junction with intestinal metaplasia. Trefoil factor 3 was ascertained as a marker of intestinal metaplasia, ${ }^{11}$ as it is the subtype most strongly associated with a risk of malignancy. ${ }^{19}$ We analysed the data according to two circumferential length cut offs, $1 \mathrm{~cm}$ or more and $2 \mathrm{~cm}$ or more, since the reliability of endoscopic diagnosis increases significantly with length. ${ }^{18}$ We defined the gastro-oesophageal junction by using the upper end of the gastric longitudinal mucosal folds as landmarks. ${ }^{20}$ To check for confounding by intestinal metaplasia of the stomach we assessed samples from the cardia and $2 \mathrm{~cm}$ above the squamocolumnar junction in all participants. If Barrett's oesophagus was present, we collected additional four biopsies every $2 \mathrm{~cm}$ according to surveillance guidelines, which were reviewed by a gastrointestinal pathologist (MO'D) with extensive experience in Barrett's oesophagus. ${ }^{19}$ Endoscopists and histopathologists were blinded to the result of the Cytosponge.

\section{Statistical analysis}

Based on assumed sensitivity and specificity of 75\% and $85 \%$ and a prevalence of Barrett's oesophagus of $3 \%$, power calculations indicated that to obtain an estimate with a $95 \%$ confidence interval plus or minus $15 \%$ we required 500 participants. Statistics for continuous variables were expressed as medians and interquartile ranges. We used a Mann-Whitney test to compare continuous or ordinal variables between groups and a $\chi^{2}$ test to compare categorical variables. Accuracy of the test was reported using Pearson Clopper exact 95\% confidence intervals. All reported $\mathrm{P}$ values were two sided. Statistical analyses were carried out using Prism V5.01.

\section{RESULTS}

Twelve general practices covering a population of 100668 were recruited over 20 months from May 2008 to December 2009 (fig 2). In total, 2696 patients identified from the practice prescribing databases were eligible and invited to take part in the study; 504 (18.7\%) agreed. The Cytosponge was successfully swallowed by 501 (99\%; three were unable to swallow). Two Cytosponges failed to fully expand and the corresponding samples had a low cell yield. All 501 participants were included in the analysis and those who did not attend for gastroscopy $(n=32)$ were considered not to have Barrett's oesophagus. No serious adverse events were associated with swallowing 
Table 1/Characteristics of participants. Values are numbers (percentages) unless stated otherwise

\begin{tabular}{|c|c|c|c|}
\hline Characteristics & $\begin{array}{l}\text { All participants } \\
\quad(n=501)\end{array}$ & $\begin{array}{c}\text { Men } \\
(n=229)\end{array}$ & $\begin{array}{l}\text { Women } \\
(n=272)\end{array}$ \\
\hline Median (range) age (years) & 62 (56 to 66$)$ & 62 (50 to 70$)$ & $62(50$ to 70$)$ \\
\hline \multicolumn{4}{|l|}{ Body mass index: } \\
\hline Missing data & $2(0.4)$ & $0(0)$ & $2(0.7)$ \\
\hline Underweight & $3(0.6)$ & $1(0.4)$ & $2(0.7)$ \\
\hline Normal & 79 (15.8) & $28(12.2)$ & $51(18.8)$ \\
\hline Pre-obese & $187(37.3)$ & $97(42.4)$ & $90(33.1)$ \\
\hline Obese & $230(45.9)$ & $103(45.0)$ & $127(46.7)$ \\
\hline \multicolumn{4}{|l|}{ Waist to hip ratio: } \\
\hline Missing data & $5(1.0)$ & $2(0.9)$ & $3(1.1)$ \\
\hline Low risk & $163(32.5)$ & $109(47.9)$ & $54(19.9)$ \\
\hline Medium risk & $136(27.1)$ & $68(29.7)$ & $68(25.0)$ \\
\hline High risk & $197(39.3)$ & $50(21.8)$ & $147(54.0)$ \\
\hline \multicolumn{4}{|l|}{ Ethnic origin: } \\
\hline White & $480(95.8)$ & $215(93.9)$ & $265(97.4)$ \\
\hline Other & $21(4.2)$ & $14(6.1)$ & $7(2.6)$ \\
\hline \multicolumn{4}{|l|}{ Education level: } \\
\hline No answer & $12(2.4)$ & $6(2.6)$ & $6(2.2)$ \\
\hline School until age16 & $234(46.7)$ & 97 (44.4) & $137(50.4)$ \\
\hline School until age 18 & $119(23.8)$ & $50(21.8)$ & $69(25.4)$ \\
\hline University degree & $36(7.2)$ & $21(9.2)$ & $15(5.5)$ \\
\hline Postgraduate/professional qualification & $100(20.0)$ & $55(24.0)$ & $45(16.5)$ \\
\hline \multicolumn{4}{|l|}{ Smoking status (pack years): } \\
\hline Never & $217(43.3)$ & $86(37.6)$ & $131(48.2)$ \\
\hline$\ll 30$ & $197(39.3)$ & $95(41.5)$ & $102(37.5)$ \\
\hline$\geq 30$ & $87(17.4)$ & $48(21.0)$ & 39 (14.3) \\
\hline \multicolumn{4}{|l|}{ Alcohol consumption (units/week): } \\
\hline None & $114(22.8)$ & $38(16.6)$ & $76(27.9)$ \\
\hline $1-15$ & $304(60.7)$ & $131(57.2)$ & $173(63.6)$ \\
\hline $16-21$ & $35(7.0)$ & $23(10.0)$ & $12(4.4)$ \\
\hline$>21$ & $48(9.6)$ & $37(16.2)$ & $11(4.0)$ \\
\hline \multicolumn{4}{|l|}{ Symptoms (GERD impact scores ${ }^{13}$ ): } \\
\hline Very well controlled & $35(7.0)$ & $20(8.7)$ & $15(5.5)$ \\
\hline Fairly controlled & 99 (19.8) & $43(18.8)$ & $56(20.6)$ \\
\hline Uncontrolled & $136(27.1)$ & 77 (33.6) & $59(21.7)$ \\
\hline Poorly controlled & $195(38.9)$ & 77 (33.6) & $118(43.4)$ \\
\hline Very poorly controlled & $36(7.2)$ & $12(5.2)$ & $24(8.8)$ \\
\hline \multicolumn{4}{|l|}{ Current use of acid suppressants: } \\
\hline Antacids & 67 (13.4) & $29(12.6)$ & $38(14.0)$ \\
\hline Histamine receptor 2 antagonists & $38(7.6)$ & $21(9.2)$ & $17(6.2)$ \\
\hline Proton pump inhibitors & $286(57.0)$ & $122(53.3)$ & $164(60.3)$ \\
\hline $\begin{array}{l}\text { Histamine receptor } 2 \text { antagonists+proton } \\
\text { pump inhibitors }\end{array}$ & $9(1.8)$ & $6(2.3)$ & $3(1.1)$ \\
\hline None & $101(20.2)$ & $51(22.3)$ & $50(18.4)$ \\
\hline
\end{tabular}

the Cytosponge, in particular no bleeding or aspiration. No failures took place in the sample processing or staining for trefoil factor 3.

Personal and clinical characteristics of participants

Table 1 shows the personal and clinical characteristics of the study population. The numbers of men and women were almost equal (male to female ratio 1:1.2) with a median age of 62 years (interquartile range
56-66 years) in both sexes. The male to female ratio (1:1.1) and median age (63 years, 58-67) of the nonresponders did not differ significantly from that of the responders. The median waist to hip ratio for men was 0.96 (interquartile range $0.92-1.00$ ), which falls within the range considered to be a medium health risk, and for women $0.86(0.82-0.91)$, which is associated with a high health risk. ${ }^{21}$ The median body mass index of 29.4 (26.2-32.9) indicated that most participants were overweight, with more than $45 \%$ in the obese range. ${ }^{22}$ Overall, participants consumed less alcohol than the national average, ${ }^{23}$ but the proportion of smokers (past and present) was 10\% higher for each sex than the national UK averages. ${ }^{24}$ Only $68 \%$ of participants (344/501) were currently taking prescribed acid suppressants, but all met the inclusion criteria of such therapy at some time in the past five years. Overall, 73\% (367/501) of participants reported uncontrolled to very poorly controlled reflux symptoms according to the impact scores for gastro-oesophageal reflux disease (table 1). ${ }^{13}$

\section{Accuracy of the test}

Based on standard gastroscopy the prevalence of Barrett's oesophagus was 3.0\% (15/501) for segments of circumferential length $1 \mathrm{~cm}$ or more and $2.2 \%(10 /$ 501) for segments of $2 \mathrm{~cm}$ or more, with a median length of C4M5 (interquartile range C1M2-C9M9) (table 2).

Table 3 shows the characteristics of the patients with a diagnosis of Barrett's oesophagus categorised according to the circumferential length of segment $(\geq 1 \mathrm{~cm}$ or $\geq 2 \mathrm{~cm})$ compared with those without Bar-

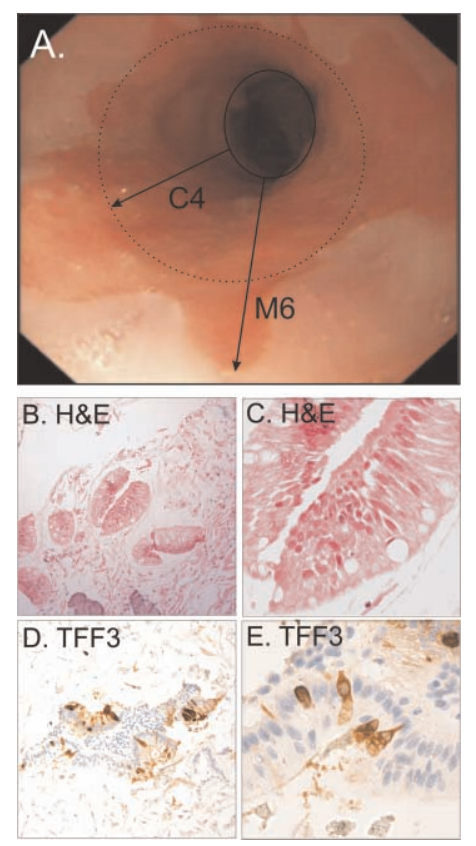

Fig 3 Endoscopic view of a patient with C2M4 segment length Barrett's oesophagus (panel A). Haematoxylin and eosin (panel $B \times 100$, panel $C \times 400$ ) and trefoil factor 3 (panel $D \times 100$, panel $E \times 400$ ) staining from representative patient with Barrett's oesophagus 
Table 2 |Characteristics of patients with diagnosed Barrett's oesophagus

\begin{tabular}{|c|c|c|c|c|c|c|c|c|c|c|c|c|c|}
\hline Patient & Sex & Age & $\begin{array}{l}\text { Body } \\
\text { mass } \\
\text { index }\end{array}$ & $\begin{array}{l}\text { Waist to } \\
\text { hip ratio }\end{array}$ & $\begin{array}{l}\text { Highest } \\
\text { educational } \\
\text { attainment }\end{array}$ & $\begin{array}{c}\text { Smoking } \\
\text { (pack } \\
\text { years) }\end{array}$ & $\begin{array}{l}\text { Alcohol } \\
\text { (units/ } \\
\text { week) }\end{array}$ & $\begin{array}{l}\text { Symptom } \\
\text { control }\end{array}$ & Drugs & $\begin{array}{c}\text { Barrett's } \\
\text { oesophagus or } \\
\text { adenocarcino- } \\
\text { ma in first } \\
\text { degree relative }\end{array}$ & $\begin{array}{c}\text { Circumfer- } \\
\text { ential } \\
\text { length }(\mathrm{cm})\end{array}$ & $\begin{array}{l}\text { Maximal } \\
\text { length } \\
(\mathrm{cm})\end{array}$ & $\begin{array}{l}\text { Cytosponge } \\
\text { test result }\end{array}$ \\
\hline \multicolumn{14}{|l|}{ Practice A: } \\
\hline Patient 1 & Male & 69 & 27.5 & 1.00 & School to 16 & 0 & 14 & Poor & Antacids & No & 1 & 3 & Positive \\
\hline \multicolumn{14}{|l|}{ Practice B: } \\
\hline Patient 1 & Male & 70 & 31.6 & 1.03 & School to 16 & 0 & 10 & $\begin{array}{l}\text { Uncontrol- } \\
\text { led }\end{array}$ & $\begin{array}{l}\text { Proton pump } \\
\text { inhibitors }\end{array}$ & No & 4 & 6 & Positive \\
\hline \multicolumn{14}{|l|}{ Practice C: } \\
\hline Patient 1 & Female & 54 & 39.8 & 0.86 & School to 16 & 0 & 2 & Poor & $\begin{array}{l}\text { Antacids+proton } \\
\text { pump inhibitors }\end{array}$ & No & 1 & 2 & Positive \\
\hline Patient 2 & Female & 58 & 27.8 & 0.89 & School to 16 & 28 & 10 & Poor & $\begin{array}{l}\text { Antacids+proton } \\
\text { pump inhibitors }\end{array}$ & No data & 4 & 6 & Positive \\
\hline Patient 3 & Female & 67 & 35.1 & 0.79 & School to 18 & 3 & 0 & Fair & $\begin{array}{l}\text { Proton pump } \\
\text { inhibitors }\end{array}$ & Yes & 2 & 2 & Positive \\
\hline Patient 4 & Male & 62 & 24.2 & 0.97 & School to 18 & 52 & 2 & Poor & $\begin{array}{l}\text { Proton pump } \\
\text { inhibitors }\end{array}$ & Yes & 1 & 4 & Negative \\
\hline \multicolumn{14}{|l|}{ Practice D: } \\
\hline Patient 1 & Male & 52 & 29.0 & 0.96 & School to 18 & 8 & 10 & Very well & Antacids & No & 6 & 6 & Positive \\
\hline \multicolumn{14}{|l|}{ Practice E: } \\
\hline Patient 1 & Female & 66 & 37.2 & 0.95 & School to 16 & 37 & 0 & Fair & $\begin{array}{l}\text { Antacids+proton } \\
\text { pump inhibitors }\end{array}$ & No & 2 & 5 & Negative \\
\hline \multicolumn{14}{|l|}{ Practice F: } \\
\hline Patient 1 & Male & 61 & 31.7 & 1.02 & School to 16 & 32 & 10 & $\begin{array}{l}\text { Uncontrol- } \\
\text { led }\end{array}$ & Antacids & No & 8 & 8 & Positive \\
\hline \multicolumn{14}{|l|}{ Practice G: } \\
\hline Patient 1 & Male & 66 & 32.4 & 1.10 & School to 16 & 31 & 2 & Poor & $\begin{array}{l}\text { Proton pump } \\
\text { inhibitors }\end{array}$ & No & 5 & 7 & Positive \\
\hline \multicolumn{14}{|l|}{ Practice H: } \\
\hline Patient 1 & Male & 64 & 24.8 & 0.86 & School to 18 & 0 & 6 & Fair & $\begin{array}{l}\text { Proton pump } \\
\text { inhibitors }\end{array}$ & No & 1 & 2 & Negative \\
\hline Patient 2 & Male & 64 & 28.4 & 0.99 & University & 28 & 1 & Very well & $\begin{array}{l}\text { Proton pump } \\
\text { inhibitors }\end{array}$ & No & 3 & 5 & Positive \\
\hline Patient 3 & Male & 59 & 23.4 & 0.92 & School to 18 & 23 & 2 & Fair & $\begin{array}{l}\text { Antacids } \\
\text { +histamine } \\
\text { receptor } 2 \\
\text { antagonists }\end{array}$ & Yes & 2 & 4 & Positive \\
\hline \multicolumn{14}{|l|}{ Practice I: } \\
\hline Patient 1 & Female & 63 & 33.5 & 0.85 & School to 16 & 0 & 0 & Poor & $\begin{array}{l}\text { Proton pump } \\
\text { inhibitors }\end{array}$ & No & 9 & 9 & Positive \\
\hline \multicolumn{14}{|l|}{ Practice J: } \\
\hline Patient 1 & Female & 70 & 32.0 & 0.83 & School to 16 & 0 & 4 & Poor & None & No & 1 & 2 & Negative \\
\hline
\end{tabular}

rett's oesophagus. No statistical differences were observed between the patients with Barrett's oesophagus $(\geq 1 \mathrm{~cm})$ and those without. If a cut off of $2 \mathrm{~cm}$ or more was used, there was a higher prevalence of tobacco smoking in patients with Barrett's oesophagus $(\mathrm{P}=0.03)$. The small sample size, however, precludes definitive conclusions.

Figure 3 shows haematoxylin and eosin and trefoil factor 3 staining of the Cytosponge specimen from a representative segment of tissue from a patient with Barrett's oesophagus. For a cut off of $1 \mathrm{~cm}$ or more, 11 of 15 segments were detected with the Cytosponge, giving a sensitivity of $73.3 \%$ (95\% confidence interval $44.9 \%$ to $92.2 \%$ ). For a cut off of $2 \mathrm{~cm}$ or more nine of 10 segments were detected, giving a sensitivity of $90.0 \%$ $(55.5 \%$ to $99.7 \%)$. The specificity was $93.8 \%(91.3 \%$ to $95.8 \%)$ and $93.5 \%(90.9 \%$ to $95.5 \%)$ for segments of 1 $\mathrm{cm}$ or more and $2 \mathrm{~cm}$ or more, respectively. The likelihood of being positive for trefoil factor 3 was statistically associated with the length of the segment affected by Barrett's oesophagus ( $\mathrm{P}=0.009$ for circumferential length and $\mathrm{P}=0.02$ for maximal length; table 2 ). Thirty false positives occurred, of which six had some evidence of columnar lined epithelium $(<1 \mathrm{~cm})$ that did not fulfil the diagnostic criteria for this study. Hence, for segments of $1 \mathrm{~cm}$ or more, trefoil factor 3 yielded a sensitivity of $73.3 \%$ (44.9\% to $92.2 \%$ ), a specificity of $93.8 \%$ (91.3\% to $95.8 \%$ ), a positive predictive value of $26.8 \%(14.2 \%$ to $42.9 \%)$, and a negative predictive value of $99.1 \%$ (97.8\% to $99.8 \%$ ) in this particular population with a prevalence of $3 \%$. Presence of intestinal metaplasia at the cardia, hiatus hernia, or oesophagitis was not associated with the likelihood of being positive for trefoil factor 3 (data not shown). 

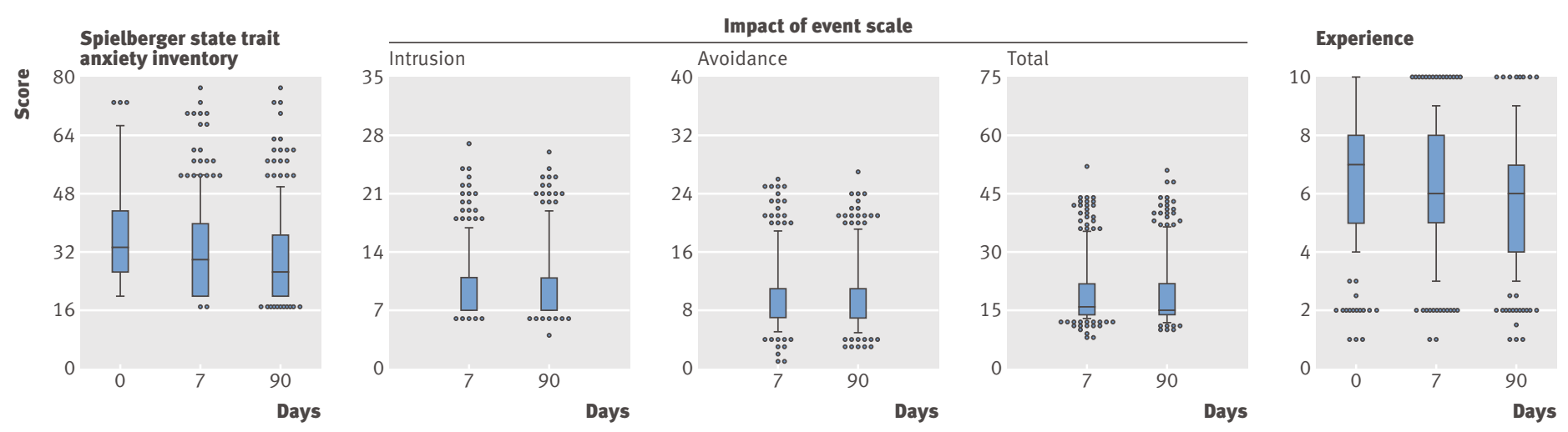

Fig 4 | Participants' experience, anxiety, and distress related to Cytosponge test. Anxiety measured at day 0,7 , and 90 using six item short form short form Spielberger state trait anxiety inventory (values $>40$ denote clinically significant anxiety). Distress associated with Cytosponge test measured using impact of events scale. Intrusion and avoidance scores $>19$ denote high impact of test and $>38$ for total score. Participants rated their experience of Cytosponge using a visual analogue scale, with 0 representing the "worst experience" and 10 the "best experience"

\section{Participant anxiety and test experience}

Response rates were high for all questionnaires at all time points: $496(99 \%)$ at baseline, $466(93 \%)$ at day 7 , and $415(83 \%)$ at day 90 . Anxiety levels were low in most patients before and after the test. A subset (141/ $496)$ of patients $(28.4 \%, 95 \%$ confidence interval $24.4 \%$ to $31.6 \%$ ) reported high anxiety scores before swallowing the sponge that remained high during follow-up. The median scores for all participants were 33.1 (interquartile range 26.6-43.3) at day $0,30.0(20.0-40.0)$ at day 7, and 26.6 (20.0-36.6) at day 90 (fig 4). The scores on the impact of event scale remained constant at days 7 and 90 after the Cytosponge test, with less than $4.5 \%$ (95\% confidence interval $2.8 \%$ to $6.1 \%)$ of participants displaying significant distress for any subscore at any time point (fig 4). The median (interquartile range) scores for the visual analogue scale were 7.0 (5.0-8.0) at the time of the test, $6.0(5.0-8.0)$ at day 7 , and $6.0(4.0-$ 7.0) at day 90 (fig 4).

\section{DISCUSSION}

The Cytosponge test is a safe and well tolerated method to screen for Barrett's oesophagus that can be carried out in a primary care setting. In this population with a history of reflux disease the prevalence of Barrett's oesophagus for a circumferential length of $1 \mathrm{~cm}$ or more was 3.0\%, for which trefoil factor 3 had a sensitivity and specificity of $73.3 \%$ and $93.8 \%$, respectively. The sensitivity increased to $90.0 \%$ for segments of $2 \mathrm{~cm}$ or more. This study was not, however, designed to estimate test characteristics with high precision, and the estimate of sensitivity has wide confidence limits. Further evaluation in a larger cohort is now warranted.

\section{Strengths and weaknesses of the study}

The attendance rate of $504(18.7 \%)$ is consistent with the $16.3 \%$ reported in a previous endoscopic study in the primary care setting. ${ }^{25}$ This should be considered in the context of a study that involved two procedures, including a hospital visit for gastroscopy. Recruitment rates for this study should not be seen as surrogate for uptake of this test if it were rolled out in a nationwide screening programme, which would be accompanied with major consumer awareness campaigns. This response bias may have resulted in people with more significant symptoms presenting or people with more positive attitudes towards receiving a screening test. Based on sex and age distribution, the non-responders and responders originated from a homogeneous population. Our preliminary data suggest that the test was

Table 3|Comparison between patients with and without Barrett's oesophagus stratified per circumferential length cut-off point of affected segment. Data are medians (interquartile ranges) unless stated otherwise

\begin{tabular}{|c|c|c|c|c|c|c|}
\hline \multirow[b]{2}{*}{ Characteristics } & \multicolumn{3}{|c|}{ Circumferential length $\geq 1 \mathrm{~cm}$} & \multicolumn{3}{|c|}{ Circumferential length $\geq 2 \mathrm{~cm}$} \\
\hline & $\begin{array}{l}\text { Barrett's oesophagus } \\
\qquad(\mathrm{n}=15)\end{array}$ & $\begin{array}{l}\text { No Barrett's oesophagus } \\
\qquad(n=486)\end{array}$ & $P$ value & $\begin{array}{l}\text { Barrett's oesophagus } \\
\qquad(n=10)\end{array}$ & $\begin{array}{l}\text { No Barrett's oesophagus } \\
\qquad(n=491)\end{array}$ & $P$ value \\
\hline Male to female ratio & $1.5: 1$ & $0.84: 1$ & 0.26 & $1.75: 1$ & $0.84: 1$ & 0.36 \\
\hline Age & $64.0(59.0$ to 67.0$)$ & $62.0(56.0$ to 66.0$)$ & 0.18 & 63.5 (58.7 to 66.2$)$ & $62.0(56.0$ to 66.0$)$ & 0.39 \\
\hline Body mass index & $31.6(27.5$ to 33.5$)$ & 29.4 (26.2 to 32.9$)$ & 0.55 & $31.6(27.8$ to 33.5$)$ & 29.4 (26.2 to 32.9$)$ & 0.59 \\
\hline Waist to hip ratio & 0.95 (0.86 to 0.99$)$ & 0.91 (0.85 to 0.96$)$ & 0.16 & $0.96(0.89$ to 1.02$)$ & 0.91 (0.85 to 0.96$)$ & 0.06 \\
\hline Smoking (pack years) & $8.0(0.0$ to 31.4$)$ & $0.4(0.0$ to 19.5$)$ & 0.30 & 23.0 (3.0 to 31.0$)$ & 0.3 (0.0 to 19.2$)$ & 0.03 \\
\hline Alcohol consumption (units/week) & $4.0(2.0$ to 10.0$)$ & $6.0(1.0$ to 14.0$)$ & 0.24 & $2.0(0.0$ to 10.0$)$ & $6.0(1.0$ to 14.0$)$ & 0.09 \\
\hline Symptoms (GERD score) ${ }^{13}$ & $4.0(2.0$ to 6.0$)$ & $4.0(2.0$ to 6.5$)$ & 0.67 & $4.0(2.0$ to 6.0$)$ & $4.0(1.7$ to 6.1$)$ & 0.99 \\
\hline Acid suppressants* $(\%)$ & 73.3 & 66.2 & 0.36 & 80.0 & 66.2 & 0.26 \\
\hline
\end{tabular}




\section{WHAT IS ALREADY KNOWN ON THIS TOPIC}

Barrett's oesophagus predisposes to oesophageal adenocarcinoma but most cases of Barrett's oesophagus are undiagnosed

Endoscopic techniques are the ideal methods for diagnosis but not easily applicable to mass screening in the primary care setting

Although emerging imaging techniques may be more applicable to primary care than endoscopy these do not permit tissue sampling, an essential component of diagnosis

\section{WHAT THIS STUDY ADDS}

The Cytosponge, a novel oesophageal sampling device, can be applied safely in the primary care setting and is well tolerated

The trefoil factor 3 biomarker when applied to the Cytosponge specimen had encouraging sensitivity and specificity for detecting Barrett's oesophagus

Screening for Barrett's oesophagus using this device warrants further evaluation

acceptable to most of those who participated in the study. Although we did not find evidence of significant psychological distress associated with the screening test in most of the participants, a subpopulation seemed to have high levels of anxiety at baseline, which persisted at day 90: this high level of anxiety may therefore have little to do with the test.

Competing technologies currently undergoing evaluation include ultrathin transnasal endoscopy and video capsule endoscopy, which remain expensive and limited to specialist centres; furthermore, endoscopy using a video capsule does not permit cell sampling, which remains a critical component for diagnosis. $^{2627}$ The sensitivity and specificity for the diagnosis of Barrett's oesophagus, even for the video capsule, remain relatively low, with values of $78 \%$ and $88 \%$, respectively. ${ }^{28}$

\section{Comparison with other studies}

The 3.0\% prevalence of Barrett's oesophagus reported here is in keeping with previous published studies. In Europe and the United States, a prevalence of 2.3-2.6\% was reported for any length of Barrett's oesophagus in patients with reflux and $0.2-0.5 \%$ for segments greater than $2 \mathrm{~cm} .{ }^{252930}$ The possibility that those who agreed to take part had more severe symptoms of reflux may explain the slightly higher prevalence reported here. Much debate has been about the clinical significance of "short segments" of Barrett's oesophagus and the presence of gastric versus intestinal metaplasia, and while carrying out this study the diagnostic criteria have continued to alter. ${ }^{31}$ However, for both circumferential length criteria $(\geq 1 \mathrm{~cm}$ and $\geq 2 \mathrm{~cm})$, the sensitivity, specificity, and negative predictive value of our Cytosponge test compared favourably with data from screening tests using mammography for breast cancer screening, prostate serum antigen testing for prostate cancer, and faecal occult blood testing for colorectal cancer. ${ }^{32-34}$ Since screening detected cases will result in endoscopic confirmation and surveillance, changes to drugs, and treatment such as radiofrequency ablation, ${ }^{635}$ we believe that the test should be designed to detect clinically significant patients who would most likely benefit from surveillance or endoscopic treatment. A screening test for Barrett's oesophagus should have high specificity to avoid unnecessary confirmatory endoscopies or interventions. Barrett's oesophagus meets many of the established criteria for population screening. ${ }^{36}$

\section{Implications for clinicians and policy makers}

Barrett's oesophagus is an important public health problem in the West ${ }^{7}$ and the metaplasia-dysplasia-adenocarcinoma sequence is well described. ${ }^{37}$ This study has shown the Cytosponge to be simple, safe, and acceptable to the population considered to be at risk (patients with reflux) and seems reasonably accurate. Furthermore, the binary scoring for trefoil factor 3 makes the test amenable to automation. Further application of risk models may be required to determine the optimal target population (symptoms only, men or both sexes, obese only). ${ }^{38}$ In the current environment endoscopic screening for Barrett's oesophagus followed by surveillance is not deemed to be cost effective. ${ }^{39}$ However, the Cytosponge might prove a more cost effective approach to screening as no hardware needs to be purchased and only minimal training is required, such that the test could be carried out by a practice nurse in the primary care setting. We are planning an in-depth cost effectiveness analysis as part of a future screening study. Furthermore, samples from the Cytosponge have the potential to be adapted for surveillance, with the application of suitable risk stratification biomarkers. ${ }^{4041}$

\section{Conclusions}

In summary, in this study we have shown that the Cytosponge coupled with a single immunomarker is a promising tool to screen for Barrett's oesophagus in the primary care setting and that further evaluation is warranted. Our data are specific to a predominantly white population in the United Kingdom. Generalisation to other communities requires a multicentre study and this would also provide more robust estimates of diagnostic accuracy. The results presented here bring screening for Barrett's oesophagus into the realm of possibility.

We thank the participants as well as the managers, general practitioners, and administrative staff of York Street Medical Practice, Linton Health Centre, Nuffield Road Medical Practice, Woodland Surgery, Willingham Surgery, Papworth Surgery, Spinney Surgery, Priory Field Surgery, Cornford House Surgery, East Barnwell Health Centre, Acorn, and Mill Road Surgery; Paul Linehan and Kareem Shariff for their help with the endoscopies; Jeanette Kersey and Pauline Wait for their administrative help; and Sarah Vowler for her statistical advice. Clinical Research Network portfolio study (ID No 1525).

Contributors: SRK ran the study and collected the data. PLS designed the study, analysed the data, and wrote the manuscript. MO'D reviewed the pathology and reviewed the Cytosponge samples. ID ran the study. MD prepared and stained the samples. JMB, JE, AB, HM, FWM, and RHH designed the study and reviewed the manuscript. PP overviewed the statistics. RCF designed the study and wrote the manuscript. RCF is guarantor for the study.

Funding: This research was supported by the Medical Research Council development gap fund, NIHR School for Primary Care Research, BD Diagnostics, Cambridge Experimental Cancer Medicine Centre, and the National Institute for Health Research Cambridge Biomedical 
Research Centre. Surepath preservative fluid was a gift from BD Diagnostics.

Competing interests: All authors have completed the Unified Competing Interest form at www.icmje.org/coi_disclosure.pdf (available on request from the corresponding author) and declare that SRK, PLS, MO'D, ID, MD $J M B, J E, A B, H M, F W M, R H H$, and RCF have no relationships with companies that might have an interest in the submitted work in the previous 3 years; their spouses, partners, or children have no financial relationships that may be relevant to the submitted work; and SRK, PLS MO'D, ID, MD, JMB, JE, AB, HM, FWM, RHH, and RCF have no non-financial interests that may be relevant to the submitted work.

Ethical approval: This study was approved by Cambridge regional ethics committee (LREC 06/Q0108/272)

Data sharing: No additional data available.

1 Shaheen NJ, Richter JE. Barrett's oesophagus. Lancet 2009;373:850-61.

2 Yousef F, Cardwell C, Cantwell MM, Galway K, Johnston BT, Murray L. The incidence of esophageal cancer and high-grade dysplasia in Barrett's esophagus: a systematic review and meta-analysis. Am Epidemiol 2008;168:237-49.

3 Medical Research Council Oesophageal Cancer Working Group. Surgical resection with or without preoperative chemotherapy in oesophageal cancer: a randomised controlled trial. Lancet 2002;359:1727-33.

4 Shaheen NJ, Sharma P, Overholt BF, Lightdale CJ, Wolfsen HC, Sampliner RE, et al. A randomized, multicenter, sham-controlled trial of radiofrequency ablation (RFA) for subjects with Barrett's esophagus (BE) containing dysplasia: interim results of the AIM Dysplasia Trial. Gastroenterology 2008;134:750-8.

5 Inadomi JM, Somsouk M, Madanick RD, Thomas JP, Shaheen NJ. A cost-utility analysis of ablative therapy for Barrett's esophagus. Gastroenterology 2009;136:2101-14.

6 Pouw RE, Wirths K, Eisendrath P, Sondermeijer CM, Ten Kate F), Fockens P, et al. Efficacy of radiofrequency ablation combined with endoscopic resection for Barrett's esophagus with early neoplasia. Clin Gastroenterol Hepatol 2009;8:23-9.

7 Donaldson L. A pathological concern: understanding the rise in oesophageal cancer. Annual report of the Chief Medical Officer. 2007.www.dh.gov.uk/prod_consum_dh/groups/dh_digitalassets/ @dh/@en/documents/digitalasset/dh_086182.pdf.

8 Crockett SD, Lippmann QK, Dellon ES, Shaheen NJ. Health-related quality of life in patients with Barrett's esophagus: a systematic review. Clin Gastroenterol Hepatol 2009;7:613-23.

9 Kruijshaar ME, Kerkhof M, Siersema PD, Steyerberg EW, Homs MY, Essink-Bot ML. The burden of upper gastrointestinal endoscopy in patients with Barrett's esophagus. Endoscopy 2006;38:873-8.

10 Wang KK, Sampliner RE. Updated guidelines 2008 for the diagnosis, surveillance and therapy of Barrett's esophagus. Am J Gastroenterol 2008;103:788-97.

11 Lao-Sirieix P, Boussioutas A, Kadri SR, O’Donovan M, Debiram I, Das M, et al. Non-endoscopic screening biomarkers for Barrett's oesophagus: from microarray analysis to the clinic. Gut 2009:58:1451-9.

12 Corder AP, Jones RH, Sadler GH, Daniels P, Johnson CD. Heartburn, oesophagitis and Barrett's oesophagus in self-medicating patients in general practice. Br J Clin Pract 1996;50:245-8.

13 Jones R, Coyne K, Wiklund I. The Gastro-oesophageal Reflux Disease Impact Scale: a patient management tool for primary care. Aliment Pharmacol Ther 2007;25:1451-9.

14 Marteau TM, Bekker H. The development of a six-item short-form of the state scale of the Spielberger State-Trait Anxiety Inventory (STAI). BrJ Clin Psychol 1992;31:301-6.

15 Horowitz M, Wilner N, Alvarez W. Impact of event scale: a measure of subjective stress. Psychosom Med 1979;41:209-18.

16 Likert R. A technique for the measurement of attitudes. Arch Psychol 1932;140:1-55.

17 Spielberger CD. Manual for the State-Trait Anxiety Inventory (form Y). Mind Garden, 1983.

18 Sharma P, Dent J, Armstrong D, Bergman JJ, Gossner L, Hoshihara Y, et al. The development and validation of an endoscopic grading system for Barrett's esophagus: the Prague C \& M criteria. Gastroenterology 2006;131:1392-9.
19 British Society of Gastroenterology. Guidelines for the diagnosis and management of Barrett's columnar-lined oesophagus. 2005. www. bsg.org.uk.

20 Amano Y, Ishimura N, Furuta K, Takahashi Y, Chinuki D, Mishima Y, et al. Which landmark results in a more consistent diagnosis of Barrett's esophagus, the gastric folds or the palisade vessels? Gastrointest Endosc 2006;64:206-11.

21 Webb GP. Nutrition: a health promotion approach. 2nd ed. Arnold, 2002.

22 World Health Organization: BMI classification. 2010. http://apps. who.int/bmi/index.jsp?introPage=intro_3.html.

23 Information Centre for Health and Social Care. Statistics on alcohol, England 2009. 2010. www.ic.nhs.uk/statistics-and-datacollections/health-and-lifestyles/alcohol/statistics-on-alcoholengland-2009-\%5Bns\%5D.

24 Information Centre for Health and Social Care. Statistics on smoking, England 2009. 2010. www.ic.nhs.uk/webfiles/publications/ smoking09/Statistics_on_smoking_England_2009.pdf.

25 Ronkainen J, Aro P, Storskrubb T, Johansson SE, Lind T, Bolling-Sternevald E, et al. Prevalence of Barrett's esophagus in the general population: an endoscopic study. Gastroenterology 2005;129:1825-31.

26 Jobe BA, Hunter JG, Chang EY, Kim CY, Eisen GM, Robinson JD, et al. Office-based unsedated small-caliber endoscopy is equivalent to conventional sedated endoscopy in screening and surveillance for Barrett's esophagus: a randomized and blinded comparison. Am J Gastroenterol 2006;101:2693-703.

27 Bhardwaj A, Hollenbeak CS, Pooran N, Mathew A. A meta-analysis of the diagnostic accuracy of esophageal capsule endoscopy for Barrett's esophagus in patients with gastroesophageal reflux disease. Am J Gastroenterol 2009;104:1533-9.

28 Ramirez FC, Akins R, Shaukat M. Screening of Barrett's esophagus with string-capsule endoscopy: a prospective blinded study of 100 consecutive patients using histology as the criterion standard. Gastrointest Endosc 2008;68:25-31.

29 Zagari RM, Fuccio L, Wallander MA, Johansson S, Fiocca R, Casanova S, et al. Gastro-oesophageal reflux symptoms, oesophagitis and Barrett's oesophagus in the general population: the Loiano-Monghidoro study. Gut 2008;57:1354-9.

30 Rex DK, Cummings OW, Shaw M, Cumings MD, Wong RKH, Vasudeva RS, et al. Screening for Barrett's esophagus in colonoscopy patients with and without heartburn. Gastroenterology 2003;125:1670-7.

31 Sharma P. Barrett's esophagus. N Engl / Med 2009;361:2548-56.

32 Weller D, Coleman D, Robertson R, Butler P, Melia J, Campbell C, et al. The UK colorectal cancer screening pilot: results of the second round of screening in England. Br J Cancer 2007;97:1601-5.

33 Mistry K, Cable G. Meta-analysis of prostate-specific antigen and digital rectal examination as screening tests for prostate carcinoma.J Am Board Fam Pract 2003;16:95-101.

34 Ferrini R, Mannino E, Ramsdell E, Hill L. Screening mammography for breast cancer: American College of Preventive Medicine practice policy statement. Am J Prev Med 1996;12:340-1.

35 Shaheen NJ, Sharma P, Overholt BF, Wolfsen HC, Sampliner RE, Wang KK, et al. Radiofrequency ablation in Barrett's esophagus with dysplasia. N Engl / Med 2009;360:2277-88.

36 UK National Screening Committee. Criteria for appraising the viability, effectiveness and appropriateness of a screening programme. 2010. www.screening.nhs.uk/criteria.

37 Wild CP, Hardie LI. Reflux, Barrett's oesophagus and adenocarcinoma: burning questions. Nat Rev Cancer 2003:3:676-84

38 Reid BJ, Li X, Galipeau PC, Vaughan TL. Barrett's oesophagus and oesophageal adenocarcinoma: time for a new synthesis. Nat Rev Cancer 2010;10:87-101.

39 Barbiere JM, Lyratzopoulos G. Cost-effectiveness of endoscopic screening followed by surveillance for Barrett's esophagus: a review. Gastroenterology 2009;137:1869-76.

40 Maley CC, Galipeau PC, Finley JC, Wongsurawat VI, Li X, Sanchez CA, et al. Genetic clonal diversity predicts progression to esophageal adenocarcinoma. Nat Genet 2006;38:468-73.

41 Jin Z, Cheng Y, Gu W, Zheng Y, Sato F, Mori Y, et al. A multicenter, double-blinded validation study of methylation biomarkers for progression prediction in Barrett's esophagus. Cancer Res 2009;69:4112-5.

Accepted: 9 July 2010 